\title{
LOLS@stigma: Comedy as activism in the changing times of the HIV epidemic
}

Authors:

Sanny Mulubale, Department of Language and Social Sciences Education, MIET Africa, University of Zambia

Poul Rohleder, Department of Psychosocial and Psychoanalytic Studies, University of Essex

Corinne Squire, Centre for Narrative Research, Department of Social Sciences, University of East London

Accepted 7 October 2020 for publication in Critical Public Health This article may not exactly replicate the final version published in the journal 


\title{
LOLS@stigma: Comedy as activism in the changing times of the HIV epidemic
}

\begin{abstract}
This paper examines how, in the midst of changing political times, some characteristics of HIV activism are changing, and suggests the relevance of these shifts for other fields of health activism. Despite the UK achieving UNAIDS's '90-90-90' testing and treatment goals, many in the UK lack up-to-date HIV knowledge and retain stigmatising attitudes, and some areas of testing failure remain. In response, people with HIV and HIV organisations are generating imaginative, collaborative projects that indicate effective contemporary forms of health activism may, as other critical health research suggests, be decentred, participatory, multimodal, affective, and implicit. The paper describes a 2016 HIV NGO-run comedy event directed at HIV awareness which was researched via qualitative pre- and post-measures, and two-month follow-up interviews. Findings pointed to strong effects of comedy, as enjoyment and 'break' in HIV thinking, feeling and action; of a one-off event's emotionality and particularity; and of performance in generating collectivity and HIV citizenship. The paper discusses the potential transferability of these findings to other health activisms, particularly around stigmatised conditions. It argues that such strategies of emotionality, multi-modality and solidarity in a performance event can work as implicit activism for changing times, generating social change via a doubled politics of resistance and alterity.
\end{abstract}

Key words: HIV, comedy, stigma, London, BAME 


\section{Introduction}

Major advances in HIV testing, treatment, and adherence have changed the character of the HIV epidemic and of HIV activism. Accessible and successful anti-retroviral therapy (ART) has assured many people with HIV of normal, healthy lifespans and removed the fear of transmitting HIV. Incidence and stigma have declined (UNAIDS, 2019). The UK has exceeded UNAIDS's 2020 targets of $90 \%$ people with HIV diagnosed, $90 \%$ of those diagnosed on treatment, and $90 \%$ of those on treatment virally suppressed. Yet it is estimated that $7 \%$ of UK people living with HIV remain undiagnosed. Many people with HIV live with poor mental health and stigma. Resource insecurity, Black and minority ethnicity, unresolved citizenship status, age and co-morbidities correlate with worse HIV outcomes. The non-HIVaffected population lacks up-to-date knowledge. Cuts in health, social and voluntary sectors mean services do not meet all treatment, care and prevention needs (APPG on HIV and AIDS, 2020; Dalton, 2016; HIV Psychosocial Network, 2018; PHE, 2019a; Stigma Survey UK, 2015).

Changes in political contexts have also changed the HIV epidemic. During the early twentyfirst century, the rise of populist, authoritarian politics intensified neoliberal ideology, while disavowing social and environmental challenges. Within public health, these shifts undermined rights- and justice-based work. Now, for instance, UK welfare policy dictates that people living with HIV must work, despite frequent fluctuating symptoms, in wellpaying jobs; or else live with considerable unmet needs, often battling a hostile benefits environment. Within the context of the medicalising success of HIV treatment (Squire, 2013), policymakers now tackle transmission less by social prevention, more by pharmacological initiatives like pre-exposure prophylaxis (PrEP), an extremely valuable programme whose socio-political complexities are however often under-recognised (Young et al., 2019). 
Reactionary populism has been accompanied by new activisms: collaborative, horizontally organised, politically articulated through lives as much as organisations, exemplified by movements like \#Metoo and \#Blacklivesmatter. In the health field, these changing activist times (Cornish et al., 2018; Lee, 2019) are exemplified by 'ground-up' engagements - for example, people with HIV campaigning, alongside people who are negative, for PrEP access in the face of restrictions (Lancet, 2016); community-based promotions of testing; HIV organisations collaborating to providing services and projects that foreground people with HIV's creative expression, for instance through music, gardening, and theatre. Such citizenactivist coalitions operate, as they have throughout the HIV pandemic (Lorway, 2017; Mbali, 2013), to resist conventional settlements, but also to generate new biopolitical formations.

We need to understand such examples of contemporary social change theoretically in relation to health activism, as above, and in relation to contemporary political activism generally. Ghassan Hage (2012) suggests that effective contemporary activisms deploy an 'alter' politics which operates aslant, rather than against, hegemonic formations to generate alternative modes of thinking, acting and feeling. Such alter-politics changes lives, but may not look like traditional activism. Hage (2012) sees it, as in climate change or \#BlackLivesMatter activism, working alongside the more conventional, struggle-oriented, 'agonistic' politics that Chantal Mouffe (2013) theorises as essential for progressive, democratic change. In neither form does negotiation to consensus deliver change. It may be useful to think about changing HIV activisms in such terms. They require actions that go beyond arbitrations between different interests, to involve radical alterities - of, for instance, the choirs, fashion shows (PHE, 2019b) and wellbeing services organised by and for people with HIV. Yet they also involve the 'agonistic' criticisms made, for example, by PrEP 
activists. In the case of activism against HIV stigma, alter-politics is generally less emphasised than a critical, destigmatising politics. A comedy performance, however, may generate 'other' activist forms of thinking, feeling and acting around HIV, aslant stigma.

This paper reports on a 2017 comedy-based HIV awareness project, LOLS@stigma (Laugh Out Loud Against Stigma), planned and delivered by a small NGO with a 15 -year history of providing HIV support and education predominantly to Black African Londoners. So far, LOLS@stigma has been the only comedy project of Public Health England's (PHE’s) HIV Prevention Innovation Fund (PHE, 2016; 2019b).

Stigma remains widely experienced by people with HIV. It has powerful negative health consequences, reducing health access and engagement; producing isolation and familial, social and workplace discrimination, which generate mental health issues; and interacting with gendered, sexual and racialised stigma (PHE, 2019a; Stigma Survey UK, 2015). The NGO worked mainly with Black African and African Caribbean-origin people, many over 50. Such groups show relatively high HIV prevalence, with plateauing incidence, high levels of late diagnosis and poorer health consequences (PHE, 2019a), and increasing incidence among older people. They are often viewed as 'hard to reach' though would be better framed as 'failed to reach' (Mbewe, 2020). These groups report similar experiences and feelings of stigma to non- black, Asian and minority ethnic (BAME) groups, but less disclosure, less formal support, and greater poverty (Stigma Survey UK, 2015).

Authors, NGO staff, and volunteers conducted research collaboratively on how LOLS@stigma worked. Analysing the findings, this paper discusses whether and how comedy is a useful modality for contemporary HIV activism; in what ways events and 
collective performances can be helpful for this activism; whether such activism might work in other health fields; and how the findings from this research relate to and develop theories of contemporary health activism and political activism more generally. ${ }^{1}$

Activism was not an overt project focus. Nevertheless, we would argue that LOLS@stigma can be understood as a form of 'implicit activism' (Horton and Krafti, 2009), operating in the everyday, at personal scale, without explicit political theorising - both, critically, 'against' stigma; and as an 'alter' engagement with HIV.

\section{HIV, activism and comedy}

Since LOLS@stigma aimed to shift people's thinking, emotions and actions around HIV, at the event and after, via a novel route, it is helpful to consider the project's relation to models of health behaviour change and activism in more detail. Many change models do not adequately consider how change happens. For instance, the popular Social Norms Approach neglects processes nested inside shifts from one health attitude or behaviour to another (Dempsey et al., 2018). Models tend to concentrate on top-down processes and individual motivation, overlooking the middle-level roles of for example communities and social movements (Keefe et al., 2006; Kippax et al., 2013). Models also often pursue simplicity, facilitating prediction, rather than addressing the complex networks of multi-levelled factors involved in health change (Kaufman et al., 2014). Instead, we tried to research change processes by addressing people's affective, thinking and action processes through a variety of qualitative methods, during and after the intervention. We attended to multiple levels through which the processes worked, from intrapersonal to transnational. We also started from service users' and NGO workers' own framings of the project and the research. 
Such an approach corresponds with current understandings of health activism for changing times as involving relationality, identity creation, coalition building, and collective agency, communication and hope, alongside new modalities (Cornish et al., 2018). The approach also draws on earlier formulations of health activism as involving 'organic' (Scambler and Kelleher, 2006) processes such as critical dialogue within safe spaces, social capital-building, and mobilisations of existing knowledge and resources (Campbell and Cornish, 2010). This extensive repertoire of health-activist change processes may feed into the broader parallel processes of critical and 'alter' politics (Hage, 2012) that, we suggest, are now likely to characterize HIV activism. Our LOLS@stigma research aimed to investigate whether these processes of health and political activism were in operation and how they related to each other.

Comedy is not common in HIV awareness programmes. Yet the collectivity of comedy shows means they are large-scale but still engaging means of disseminating information. Comedy has been a successful part of HIV participatory theatre, broadcast media, and film (e.g. Blumberg, 2011; Christiansen and Hansen, 2009). UK African comedy's social value has also been noted in theatre, rap and spoken word (Goddard, 2015) - relevant findings given LOLS@stigma’s planned African and African Caribbean audiences.

Now that HIV is understood as a 'chronic', not fatal, condition, audiences may be more open to HIV-related comedy (Curry, 2017). Although the past of HIV still fuels present fears, comedy generates positive affect that reduces defensiveness and shame, enabling engagement with challenging health messages (Hendricks and Janssen, 2018; Yoon, 2018). Positive affect like that generated by comedy is increasingly recognised as important for health behaviour change (Van Cappellen et al., 2018), and positive emotions are central to theories of 
contemporary activism generally (Cornish et al., 2018). Comedy might thus progress HIV attitudes by providing an emotional climate conducive to knowledge acquisition, stigma reduction, and action. In addition, comedy may work through providing affective 'relief', and its disruptive incongruity may break HIV taboos, enabling conversation (O'Shannon, 2012). Indeed, Lewin's early work on organizational change suggested an initial 'unfreezing' process, similar to comedy's disruptive break (Batras et al., 2016).

LOLS@stigma assumed that a single event - an occurrence specified in space and time could generate change. HIV prevention theory and practice favour long-term, comprehensive initiatives (UNAIDS, 2016), and little research examines longer-term event effects. Yet events can have lasting positive impact, affecting for instance emotional elements of attitudes and openness, even when their content is not clearly remembered; and making a nonreversible 'break' (Pavis, 2007; Taggart et al, 2016). An 'event' can also be conceptualized within contemporary multi-levelled and process-oriented models of health activism (Kaufman et al., 2014). It does not focus only on individuals; nor can it be explained simply as an assemblage of social structures. While it constitutes a break, it is also processual, making connections across the times and spaces in which it happens, and opening up new contexts, including those of the future (Derrida, 1988).

The LOLS@stigma project was in addition a performance, which means that it was an event which expressed meaning, using some aspects of human bodies, to an audience. Research suggests diversity in performance modalities, as in this project, and audience involvement, are effective change agents (Chizisa, 2019; Pavis, 2007); they parallel the organicity and the media and processual complexity emphasised by theorists of contemporary health activism (Cornish et al., 2018; Kaufman et al., 2014; Scambler and Kelleher, 2007). LOLS@stigma 
was not conventionally participatory, but it involved audience responses and arose directly from dialogue between NGO workers, often themselves positive, service users, and their networks.

\section{Method}

Preparation

LOLS@stigma was a night of comedy in a central London music venue. Beforehand, the two comedians, both well-known African-origin performers, received HIV information to help their preparation. They chose general rather than HIV-related material, so the audience experienced comedy in association with rather than directly related to HIV issues. However, the comedians made repeated positive references to the event's HIV remit. Their performances were interspersed with two motivational speakers with HIV, who conveyed destigmatising HIV information, and also adopted a humorous tone.

The NGO advertised LOLS@stigma widely through social media and personal networks, to service users and wider London African and African-Caribbean communities, as a comedy and HIV awareness event aimed at reducing HIV stigma. A small entrance fee was charged to cover (discounted) venue hire and performers' fees. The venue included HIV information at the entrance, posters and slide projections throughout, and NGO staff and volunteers, many HIV positive themselves, giving advice. There was a DJ, a rap performance, and fundraising and volunteer recruitment at the entrance. Rapid HIV testing was provided alongside related health advice in a private room. A pay bar and snacks were available. The NGO's online resources were flagged throughout, and in follow-up messages to attenders. 


\section{Data collection}

Methods were piloted with 11 second-year University of East London (UEL) students who came from BAME backgrounds and were close in age range to those of LOLS@stigma target participants, including several over 50. The study was approved by UEL's ethics panel and the NGO involved. Research took a multi-modal approach, eliciting written and verbal associative, semi-structured, and structured responses, pre - and post-event. These multiple routes to knowledge were helpful because research was not attenders' priority. Research also included a small sample two-month interview follow-up.

'Feedback' packs of research documents were distributed to 155 attenders either at entry or at their seats. Packs contained:

- an information sheet and consent form;

- a demographics information sheet;

- a pre- and post- event word association task, asking participants to note three words or phrases they associated with HIV before and after the event;

- a post-event one-page Likert-scale questionnaire, exploring participant perceptions of event-induced changes in conventional attitude components of thinking, feeling and action (Eagly and Chaiken, 1993) around HIV; different event elements' perceived value; and open comments.

- a research recontact form, and an advice recontact form which, if completed, allowed the NGO to provide further information and advice.

All documents except the last displayed attender-specific numbers.

Attenders were briefed on the research at entry or at their seats. The MC (master of ceremony) announced the research activities at the event's beginning and end; UEL team 
members also explained them from the stage. Instructions given, for instance about completing all documents, were not always followed, but too-frequent or insistent instructions would have detracted from the event's pleasurable atmosphere.

The project's focus on building awareness may have affected how audience members responded, encouraging them to foreground positive effects. Nevertheless, differences between pre- and post-event response sets could usefully be related to the event's specific 'comedy' character. It was also inevitable that pre- and post-measures would themselves operate as interventions, as well as research, since they encouraged people to reflect on their HIV perspectives before and after the event.

Due to noise and lack of privacy, interviews were not conducted at the event. Follow-up interviews were conducted two months after the event, at end September 2017. Eighteen attenders indicated willingness to be recontacted, with anonymity maintained by participant number only being linked with cellphone number or - if available - an unnamed email. Contact with 13 participants generated interviews with six; others could not be reached, or declined. This attrition was not surprising since the study could meet few criteria associated with longitudinal research retention (Vincent et al., 2012). The restricted number of interviewees meant the follow-up had limited value. It remains useful though, particularly in the light of little follow-up in this timeframe in similar projects.

Interviews were by telephone as participants were spread across and outside London and had limited availability. Interviews began with oral consent form and questionnaire readministration to determine whether attenders’ perspectives on LOLS@stigma had changed over time, and then qualitatively explored participants' own original and follow-up 
questionnaire responses. Since post-event questionnaire responses had been overwhelmingly positive, we also asked participants aboutLOLS@stigma's limitations, and what could be improved in future projects.

We did not address 'activism' directly with participants. Rather, in keeping with our understanding of contemporary HIV activism as often implicit, particularly when it takes the form of lived alterities, we took participants' responses around changes in thinking, feeling and action as proxies for activism.

Analysis

Questionnaire and demographic information were given descriptive statistical analysis. Thematic content analyses (Braun and Clarke, 2013) were conducted of the pre- and postevent word associations, responses to open-ended questionnaire items, and follow-up interviews.

\section{Findings}

Evaluation packs were distributed to all 155 attenders and responses collected from 84 (54\%). Incomplete responses were frequent, probably due to the event's entertainmentoriented nature. Post-event materials were less completed than pre-event materials, likely because the event's late running meant people had to hurry home. A comedy show was a new context for the researchers; research experience in entertainment environments might have improved findings' reliability. 


\section{Demographics}

Sixty-five participants completed the pre-event demographic information sheet. Participant characteristics are shown in Table 1.

Table 1: Participant characteristics

\begin{tabular}{|c|c|c|c|}
\hline Feature & Description & Frequency & Per cent $(\%)$ \\
\hline \multirow{3}{*}{$\begin{array}{l}\text { Gender } \\
\text { (Responses: } n=65 \text { ) }\end{array}$} & Men & 18 & 28 \\
\hline & Women & 42 & 66 \\
\hline & Transgender/Other & 5 & 6 \\
\hline \multirow{7}{*}{$\begin{array}{l}\text { Age } \\
\text { (Responses: } n=65 \text { ) }\end{array}$} & $18-24$ & 7 & 11 \\
\hline & $25-34$ & 14 & 22 \\
\hline & $35-44$ & 13 & 20 \\
\hline & $45-54$ & 12 & 18 \\
\hline & $55-64$ & 14 & 22 \\
\hline & $65+$ & 4 & 6 \\
\hline & Prefer not to say & 1 & 3 \\
\hline \multirow{5}{*}{$\begin{array}{l}\text { Ethnicities } \\
\text { (Responses: } n=62 \text { ) }\end{array}$} & Black African & 37 & 60 \\
\hline & Black Caribbean & 16 & 26 \\
\hline & Asian & 2 & 3 \\
\hline & White & 4 & 4 \\
\hline & Other & 3 & 3 \\
\hline \multirow{4}{*}{$\begin{array}{l}\text { Sexualities } \\
\text { (Responses: } n=54 \text { ) }\end{array}$} & Gay or lesbian & 1 & 2 \\
\hline & Bisexual & 3 & 6 \\
\hline & Heterosexual & 33 & 61 \\
\hline & Other & 14 & 25 \\
\hline
\end{tabular}




\begin{tabular}{|l|l|l|l|}
\hline & Prefer not to say & 3 & 6 \\
\hline \multirow{2}{*}{ Residence } & London & 54 & \\
\cline { 2 - 4 } & Outside London & 11 & \\
& & & \\
\hline
\end{tabular}

Ages were widely distributed, with around $37 \%$ in the over 50 group which now accounts for one-third of people with HIV, and which is especially likely to be diagnosed late - a group of interest for this project.

Nineteen of 33 (58\%) London boroughs were represented, including many with over 5 per 1000 HIV prevalence. The project thus did well in attracting attenders London-wide, and from salient locations.

Table 2: Pre- and post-event perceived levels of HIV knowledge and involvement

\begin{tabular}{|l|l|l|l|l|}
\hline Knowledge levels & \multicolumn{2}{l|}{$\begin{array}{l}\text { Pre - event } \\
(\mathbf{n}=\mathbf{6 4})\end{array}$} & \multicolumn{2}{l|}{$\begin{array}{l}\text { Post - event } \\
(\mathbf{n}=60)\end{array}$} \\
\hline Good or very good & 36 & $57 \%$ & 47 & $78 \%$ \\
\hline Average or below & 28 & $43 \%$ & 13 & $22 \%$ \\
\hline Total & 64 & $100 \%$ & 60 & $100 \%$ \\
\hline
\end{tabular}

Table 2 shows $43 \%$ of participants self-reporting average or below-average pre-event knowledge. Reaching such people is important in the context of low general population HIV knowledge, and high percentages of late diagnoses in BAME groups like those at this event. 
Higher post-event reported knowledge suggests a strong event effect. However, an expectation effect may also have operated.

Since HIV organisations often address interested and knowledgeable communities, the $61 \%$ of respondents who described themselves as not very or not at all involved with HIV was important, especially given the highly HIV-affected and late-diagnosed nature of BAME groups from which most attendees came.

Pre- and post-event 'three words or phrases' exercise

Sixty-seven pre-event and 24 post-event word association exercises were collected. Of the latter, six had not completed a pre-event exercise. From observation, the highly engaging preevent exercise valuably inducted participants into the research.

Across responses, no clear differences appeared around gender, age, ethnicity, sexuality, place of residence, route to the event, or level of HIV knowledge and engagement. Some expectation effect may have operated. However, pre-event words and phrases were almost entirely negative, post-event words and phrases almost entirely positive. We cannot reliably test the significance of this variably-sized lexical sample, but we report themes below: 
Figure 1: Pre and post - event themes

\section{Pre-event themes (in descending order of frequency):}

- Fatalism (e.g. death, terminal, suffering)

- Knowledge (e.g. disease, sexually transmitted, needles)

- Emotions (e.g. fear, loneliness)

- Social dynamics (e.g. stigma, discrimination)

- Identity (e.g. Africa, gay)

\section{Post-event themes (in descending order of frequency):}

- Optimism (e.g. hope; life)

- Action (awareness; education; testing)

- Knowledge (normal lifespan; medication)

Pre-event words and phrases associated HIV with death, suffering, stigma and discrimination. Post-event words and phrases incorporated many event messages. Themes centred on optimism derived from knowing HIV is a manageable illness, and included words associated with knowledge, positive emotions and action, for example 'awareness', 'hope', normality', 'testing'.

\section{Post-event questionnaire}

The questionnaire was completed by 43 audience members. The greater number of respondents compared to the 24 post-event 'three words and phrases' respondents might be because of higher perceived salience of this measure. Many questionnaires were incomplete, and there were ceiling effects on many items, with $74 \%-86 \%$ agreeing or strongly agreeing 
that the event would affect how they thought, felt and acted. Given these data and measurement limitations, we provide a descriptive account below, concentrating on perceived effects of the event and value of its main elements.

Again, no clear differences emerged relating to demographic factors, route to the event, or level of HIV knowledge and engagement. Thirty-four respondents (79\%) agreed or strongly agreed they had learnt a great deal from the event. Thirty-seven (86\%) reported positive or very positive feelings about the event-a strong endorsement of the affective element of the event's attitudinal effects. Thirty-two (74\%) agreed or strongly agreed that the event would have some effects on their life. Two of seven respondents providing open-ended comments stated they wanted to learn more about HIV. 'I hope you do this kind of event every four months so you can educate more people', one said.

Comedians and speakers, who were openly HIV positive, optimistic and humorous in their presentations, were the most approved event elements. Comedy had a stronger positive effect, with $69 \%$ of respondents endorsing this element very positively, $28 \%$ positively. This positivity may have been partly an artefact of the event's declared comedy orientation. The comedy performers themselves presented some motivational elements, talking affirmatively about HIV and encouraging positive approaches to it, so it is not easy to disentangle comedy from motivational effects.

'Positive' and 'very positive' responses to HIV testing opportunities were high ( $45 \%$ each). 


\section{Follow-up interviews}

Six attendees participated in telephone interviews: four women and two men, all selfdescribed as heterosexual, three between 25 and 34 and three between 45 and 54 . Three identified as Black African and three as Asian. Two had helped at the event as well as attending. Despite greater involvement, their responses were close to those of other attenders. While the sample was small, the extended, complex nature of this material makes it worth reporting at some length.

Post-event questionnaires' high levels of self-reported knowledge gain, positive feelings, and motivations to act were re-affirmed at follow-up. Although recall of specific event messages and reports of specific actions were low, HIV-related intentions were positive, as with Christine (all names are pseudonyms), who reported now being motivated to get tested regularly. Reflecting on levels of self-reported prior knowledge, Rose suggested these reports were not reliable. 'Many HIV positive people are themselves not that knowledgeable', she said, suggesting that even positive attenders may have overestimated their prior knowledge.

Participants again expressed positive views about comedy's usefulness for HIV awareness. Rose suggested comedy worked because it constituted a break, causing people to think differently and take a novel, 'why not?' approach. Two participants noted that the concommittant focus on HIV needed to be strong. Rose thought HIV-aware and sensitive comedy should work within an HIV information-rich context, as in this case. Christine thought the comedians could have said more about HIV:

Christine: Hm they (the comedy acts) were alright; it was interesting. But I think, maybe they would have put more of their comedy into the subject. They entertained 
us but maybe they could have added more to the subject which was being addressed that day.

The enjoyment associated with comedy dominated participant memories. Their calls for future events were also associated with enjoyment. Alicia described how much she had enjoyed the event before saying she would attend another one. Rose talked about the good time they had had before suggesting the NGO keep doing similar events. Carl, a participant who was also a volunteer, suggested the event be held annually.

Motivational speakers' messages had faded by the time of the interviews. Alicia stated that she didn't remember anything the speakers had said. Rose also noted she couldn't remember the speeches' content, or even if there had been one or two speakers. She remembered, however, the comedic and enjoyable aspects of one speech. The speakers were also remembered as having considerable impact at the time:

Christine: They were quite interesting and I think they were on point. I think they managed to reach a lot of people.

Four follow-up interviews indicated very positive responses to the event's testing opportunities. Rose suggested the event would have encouraged others to test. Christine indicated a personal effect:

Christine: I think it is going to have a positive effect on both testing and the way I see life, how people living with HIV are going to think about life hm. It is about people 
motivated to get tested. And then, because there is life after being tested and people can live a normal life.

However, Carl (a participant-volunteer) suggested many attendees were not aware of the event testing opportunities, despite announcements - a perception shared by Rose. Anne (another participant-volunteer) specified the downsides of testing during the event: The intrinsic contradiction between HIV testing and comedy, and difficulties addressing medical issues in a public environment.

\section{Discussion}

This study's first question was whether and how comedy might be a useful modality for contemporary HIV activism. Positive shifts between pre- and post-event HIV associations, and positive assessments of comedy in post-event evaluations and interviews, suggest LOLS@stigma’s comedy focus was indeed valuable for HIV awareness. As Hendriks and Janssen (2018) and Yoon (2018) found, humour bypassed fear and shame to allow engagement with HIV. Its incongruity generated an 'unfreezing' Lewinian break, and consequent relief, epitomised by participants' unexpected positive feelings of laughing 'against' HIV stigma. Comedy allowed audiences to practice, as Hage (2012) describes, both a stigma-resistant politics - not always easy to achieve when stigma shuts off discussions and decisions between people about HIV - and an affective 'alter' politics, with politics literally felt as laughter in the body- something particularly uncommon around HIV and stigma. Comedy seems to have generated these parallel spaces of implicit but powerful activism. It achieved this, as recent theories of health activism would indicate (Campbell and Cornish, 2010; Cornish et al., 2018; Kaufman et al., 2014; Keefe et al., 2006), by opening up a safe, socially supportive ecosystem in which to expand HIV knowledge, affect, and action. The 
pleasure, disruptiveness and collectivity of this comedy-based approach might, we suggest, succeed within activisms around other stigmatised conditions - for instance, other sexually transmitted infections, mental distress, and disabilities.

This intervention was a single show, therefore involving the modality of an event. While the event's particularities were poorly remembered in follow-up, interviewees clearly recalled its pleasurable character, including in relation to behavioural intentions. This recall supported prior work on events' affective and long-term effectiveness, and on the value of affect for contemporary activism generally (Cornish et al., 2018; Pavis, 2007; Taggart et al., 2016). Questionnaire and interview responses also suggested the event's particularity was impactful, leading participants to imagine and request its repetition (Derrida, 1988), and in this process, generating openness in the event's effects (Pavis, 2007). For instance, in imagining future events, participants suggested going beyond LOLS@stigma’s geographical and financial restrictions, to enable more participation by people with HIV who were resource-constrained. It may be that such particular and pleasurable events are more effective as activism than conventionally thought - again, particularly around stigmatised conditions, where they can operate, literally at the same moment, in critical, destigmatising and 'alter', enjoyable ways.

LOLS@stigma also worked as performance. Attenders reported thinking and feeling positively, immediately afterwards and later, about all performance modalities contributing to the event - comedy, speeches and testing, for instance - supporting suggestions that diverse performance media are important for activism (Cornish et al., 2018; Pavis, 2007). Attenders' own responses - laughing, applauding, dancing, discussing the entertainment and information - also operated as performance modalities. Such pleasurable participatory performance also characterises events like World AIDS Day, and Breast Cancer, Lung Cancer and Prostate 
Cancer Awareness Months, which all have measurable effects on testing. LOLS@stigma suggests that for audiences addressing stigmatisation, participatory engagement with multimodal performance may have specific value, especially for facilitating alter-political openness and exploration.

Findings also included strong affirmations of the hopeful, solidaristic collectivity experienced around performance. Attenders enjoyed and wanted to repeat this collective identity. They saw themselves as acting on it, both directly, through testing, and more generally, as new 'implicit activists', through their own changed knowledge and feelings about HIV. Such findings indicate that collective aspects of performance can catalyse the relationality and connection of contemporary health activist-citizens (Cornish et al., 2018). The findings also suggest that performance-generated collectivity may have effects beyond those achieved by information-centred, medicalised and individualised interventions, indicating that it might be useful around other hard-to-address chronic health issues like heart disease and Type 2 diabetes. Again, this 'collectivist' activist technology may be helpful in facilitating alterpolitical openness and exploration, as well as generating critical approaches.

\section{Research challenges}

Several logistical issues arose within this research, for instance time overspills, and low follow-up response rates. These issues are part of the methodological 'messiness' (Ahmed, 2017) often encountered when researching health activisms collaboratively with NGOs or others. We turn now to three significant aspects of this productive messiness.

Pursuing research alongside a comedy show meant participant attention was limited. However, the comedy generated LOLS@stigma’s enveloping, ‘feel-good' atmosphere, which 
contributed to its effectiveness. Using different methods and time points was a way to keep people involved. The 'three words and phrases' exercise's ease and informality brought people into the research and allowed them to write freely about negative aspects of HIV, including stigma. Survey and demographic forms provided more systematic post-event views. Follow-up interviews encouraged attenders to reflect on the event at critical distance.

From questionnaire comments and interviews, more HIV-centred comedy would be a possible modification for future events. Yet comedy about HIV may still not 'work' for all. The well-remembered humorous and other affective aspects of motivational speeches suggested HIV might best be addressed comedically by people with HIV themselves 'owning' the comedy, as is now common with comedy made by and for people with disabilities. Comedy might therefore add to existing UK activist traditions of music, theatre and dance performance made by people with HIV themselves (Cornish et al., 2018).

Finally, health issues are also broader, structural issues. People think, feel and act about HIV within patterns of gendered and racialised inequality, for instance. This single event could not fully address such issues; nor was it designed to build social capitals long-term, or to explore and build existing capacities (Campbell and Cornish, 2010). Participants' requests for the event to repeat and develop, for its 'alter'-HIV citizenship to grow, demonstrated how the limitations of activist projects may be addressed by participants themselves. Yet scale-up was impossible, given fixed funding. Indeed, funding cuts have now closed the organising NGO. 


\section{Conclusions}

This study indicates that modes of HIV activism are changing, within a contemporary political climate that often ignores traditional liberal discourses and practices of health rights, to more decentred, heterogeneous, affective and implicit forms (Cornish et al., 2018; Horton and Krafti, 2009). In the case of LOLS@stigma, comedy’s affect, bodily experienced; its sociality; and its unfreezing 'break' worked as effective means of shifting people's thoughts, feeling and actions about HIV. We suggest that comedy could achieve something similar for other stigmatised health conditions.

The pleasure and particularity of this event generated long-lasting new relations to HIV, indicating that one-off events might be powerful resources for other stigma-resisting health activisms too. The enjoyable, multimodal and collective performance aspects of LOLS@stigma, which generated hope, relationality, and moments of HIV citizenship, also have broader potential applications within health activisms.

Findings from the research supported prior descriptions of activisms in changing times as moving towards participation, emotionality, and multimodality (Cornish et al., 2018; Kaufman et al., 2014; Kress, 2010; Scambler and Kelleher, 2006). Such processes also appeared to contribute to broader contemporary political change processes, described by Hage (2012) as involving a paralleling of critical, 'agonistic' (Mouffe, 2013) with 'alterpolitical' politics. Bringing people together to laugh and to talk about subjects often silenced and rarely associated with laughter seemed valuable for participants. Affect-laden memories of this positive collectivity informed later HIV understandings. LOLS@stigma thus acted both as an explicit resistance to HIV stigma, and as an alter-politics of HIV that showed 'we can be/are other than what we are/seem to be' (Hage, 2012:303). 


\section{Acknowledgements}

We would like to thank Amanda Amito, Mark Carew, Alice Mukaka and Luis Vasconceles for their invaluable contributions to this project.

\section{Funding}

Kwa-Africa; Public Health England. Innovative Prevention Fund

\section{References}

Ahmed, S. (2017). Living a feminist life. Durham, NC: Duke University Press.

APPG on HIV and AIDS. (2020). The missing link. London.

https://static1.squarespace.com/static/5b7d333855b02cc3853805ce/t/5e60ec83633a0705fb4d

4a32/1583410309413/The+Missing+Link+Web+version.pdf. Accessed 27.7.20.

Batras, D., Duff, C. and Smith, B. (2016). Organisational change theory: Implications for health promotion practice. Health Promotion International 31, 1: 231-41.

Blumberg, M. (2011). Staging AIDS. South African Theatre Journal. 11, 1: 155-82.

Braun, V. and Clarke, V. (2013). Successful qualitative research. London: Sage.

Campbell, C. and Cornish, F. (2010). Towards a 'fourth generation' of approaches to HIV/AIDS management. AIDS Care 22, Supplement 2: 1569-79. 
http://eprints.1se.ac.uk/32179/1/Towards_a_fourth_generation_of_approaches_to_HIV_AIDS _management_\%28publisher_version\%29.pdf. Accessed 27.7.20.

Chizisa, Z. (2019). Using the theatre for development to engage boys in examining masculinity and HIV in two Malawi schools. Journal of Applied Arts and Health 10, 1: 8798.

https://www.ingentaconnect.com/content/intellect/jaah/2019/00000010/00000001/art00007 Accessed 27.7.20.

Christiansen, A. and Hansen, J. (2009). Comedy as a cure for tragedy. Quarterly Journal of Speech. 82, 1: 157-70.

Cornish, F., Campbell, C., and Montenegro, C. (2018). Activism in changing times: reinvigorating community psychology-introduction to the special thematic section. Journal of Social and Political Psychology, 6, 2: 526-42.

Curry, T. (2017). Can comedy help erase the stigma of HIV? Dazed http://www.dazeddigital.com/artsandculture/article/35589/1/can-comedy-help-erase-thestigma-of-hiv. Accessed 27.7.20.

Dalton, D. (2016). Cutting the ribbon? University of Sunderland. https://drive.google.com/file/d/0B81ADjHBHuoeb3R3YUo0MU9SMmM/view?pref=2\&pli= 1. Accessed 27.7.20. 
Dempsey, R., McAlaney, J. and Bewick, B. (2018). A critical appraisal of the social norms approach as an interventional strategy for health-related behavior and attitude change. Frontiers in Psychology 9: 2180. doi: 10.3389/fpsyg.2018.02180. Accessed 27.7.20.

Derrida, J. (1988). Limited Inc. Chicago: Northwestern University Press.

Eagly, A.and Chaiken, S. (1993). The psychology of attitudes. New York : Harcourt Brace.

Goddard, L. (2015). A slice-of-life: British African social comedy in Bola Agbaje's council estate plays. In L. Goddard Contemporary Black British playwrights. London: Palgrave Macmillan.

Hage, G. (2012). Critical anthropological thought and the radical political imaginary today. Critique of Anthropology 32, 3: 285-308.

Hendriks, H. and Janssen, L. (2018). Frightfully funny: combining threat and humour in health messages for men and women, Psychology \& Health, 33, 5: 594-613,

HIV Psychosocial Network (2018). Ten Years After: An ‘Austerity Audit' of Services and Living Conditions for People Living with HIV in the UK, a Decade after the Financial Crisis. https://repository.uel.ac.uk/item/8818v Accessed 20.6.20.

Horton, J. and Krafti, K. (2009). Small acts, kind words and 'not too much fuss': implicit activisms. Emotion, Space and Society 2, 1: 14-23. 
Kaufman, M., Cornish, F., Zimmerman, and Johnson, B. (2014). Health behaviour change models for HIV prevention and AIDS Care. Journal of Acquired Immune Deficieny Syndrome 66, Supplement 3: S250-8.

https://www.ncbi.nlm.nih.gov/pmc/articles/PMC4536982/

Keefe, R., Lane, S. and Swarts, H. (2006). From the bottom up. Journal of Health \& Social Policy, 21, 3: 55-69.

Kippax, S., Stephenson, N., Parker, R. and Aggleton, P. (2013). Between individual agency and structure in HIV prevention. American Journal of Public Health 103, 8: 1367-75.

Kress, G. (2010). Multimodality. London: Routledge.

Lancet (2016). UK PrEP decision reignites HIV activism. April 9. https://www.thelancet.com/journals/lancet/article/PIIS0140-6736(16)30186-6/fulltext. Accessed 27.7.20.

Lee, R. (2019). Art, activism and the academy. Journal of Southern African Studies, 45, 1: 113-19.

Lorway, R. (2017). AIDS activism, science and community across three continents. New York: Springer.

Mbali, M. (2013). South African AIDS activism and global health politics. 
London: Palgrave.

Mbewe, R. (2020). Introductory speech, launch of the APPG report on HIV and mental health, London, March.

Mouffe, C. (2013). Agonistics. London: Verso.

O'Shannon, D. (2012). What are you laughing at? London: Continuum.

Pavis, P. (2007). Theatre analysis. New Theatre Quarterly 1, 2: 208-12.

PHE (2016). Health Matters: A look at the HIV Prevention Innovation Fund. London: PHE. https://publichealthmatters.blog.gov.uk/2016/12/01/health-matters-a-look-at-the-hivprevention-innovation-fund/.

PHE (2019a). Trends in new HIV diagnoses and in people receiving HIV-related care in the United Kingdom. London: PHE.

https://assets.publishing.service.gov.uk/government/uploads/system/uploads/attachment_data /file/835084/hpr3119_hiv18-v2.pdf. Accessed 27.7.20

PHE (2019b). Innovative HIV prevention projects reached 170,000 in 2018. London: PHE. https://www.gov.uk/government/news/innovative-hiv-prevention-projects-reached-170000people-in-2018. Accessed 27.7.20. 
Scambler, G. and Kelleher, D. (2006). New social and health movements. Critical Public Health, 16, 3: 219-31.

Squire, C. (2013). Living with HIV and ART. London: Palgrave.

Stigma Survey UK (2015). HIV in the UK.

http://www.stigmaindexuk.org/reports/2016/NationalReport.pdf. Accessed 27.7.20.

Taggart, T., Taboada, A., Stein, J., Milburn, N., Gere, D. and Lightfoot, A. (2016). AMP! A cross-site analysis of the effects of a theatre-based intervention on adolescent awareness, attitudes and knowledge about HIV. Prevention Science 17: 544-53.

UNAIDS (2019). UNAIDS data 2019. Geneva: UNAIDS.

https://www.unaids.org/sites/default/files/media_asset/2019-UNAIDS-data_en.pdf. Accessed 27.2.20.

UNAIDS (2016). Get on the fast track. Geneva: UNAIDS.

http://www.unaids.org/sites/default/files/media_asset/Get-on-the-Fast-Track_en.pdf. Accessed 27.7.20.

Van Cappellen, P., Rice, E., Catalino, L. and Fredrickson, B. (2018). Positive affective processes underlie positive health behaviour change. Psychology \& Health, 33, 1: 77-97. 
Vincent, K., Kasperski, S., Caldeira, K., Garnier-Dykstra, L., Pinchevsky, G., O’Grady, K. and Arria, A. (2012). Maintaining superior follow-up rates in a longitudinal study. International Journal of Multiple Research Approaches. 6, 1: 4406.

https://www.ncbi.nlm.nih.gov/pmc/articles/PMC3255097/. Accessed 27.7.20.

Young, I., Davis, M., Flowers, P., and McDaid, L. M. (2019). Navigating HIV citizenship: identities, risks and biological citizenship in the treatment as prevention era. Health, Risk \& Society, 21, 1-2: 1-16.

Yoon, H. (2018). Using humour to increase effectiveness of shameful health issue advertising. International Journal of Advertising, 37, 6: 914-36.

\footnotetext{
${ }^{1}$ For the full report, contact authors.
} 